\title{
TITLE:
}

\section{Geriatrics in the most aged country, Japan}

AUTHOR(S):

Arai, Hidenori

\section{CITATION:}

Arai, Hidenori. Geriatrics in the most aged country, Japan. Archives of Gerontology and Geriatrics 2009, 49(Supplement 2): S1-S2

ISSUE DATE:

2009-12

URL:

http://hdl.handle.net/2433/128947

\section{RIGHT:}

(c) 2009 Elsevier Ltd; この論文は出版社版でありません。引用の際には 出版社版をご確認ご利用ください。; This is not the published version. Please cite only the published version. 
Geriatrics in the most aged country, Japan

pap1201(R)

\section{Hidenori Arai ${ }^{\mathrm{a}}$}

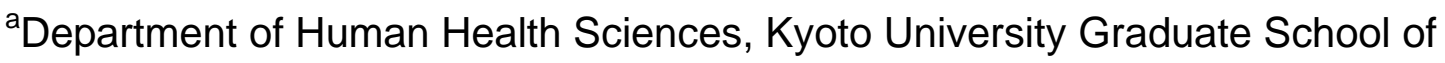
Medicine, 53 Kawahara-cho, Shogoin, Sakyo-ku, Kyoto 606-8507, Japan 
Phone/fax: +(81-75)-751-3861

E-mail: harai@kuhp.kyoto-u.ac.jp 


\section{Abstract}

The aging of society is a common problem in many developed countries. To tackle the problems related to an aging society, the role of geriatricians, as well as government support, is becoming more and more important. There is need to recruit young physicians with the skills required to care for elderly patients, and to establish an education system which encourages more young physicians to undertake training in geriatrics. Additionally, there is a need for improvement of our insurance systems to support such care. Our approach to the aging society will pave the way for other countries in Asia and the west.

Keywords: Aging society, long-term care insurance, comprehensive geriatric assessment, health care system

\section{Aging of society in Japan}

The aging of society is a phenomenon affecting many developed countries in the west and Asia (Khaw, 1999; Imuta et al., 2001). Among them, Japan has the highest proportion of over-65s in the world: $22.1 \%$ in 2008 . Further, $10.4 \%$ of the total population is over 75 , making Japan the first country to have over $10 \%$ of the population in this very elderly range. In addition, we have also the longest average life span in the world: the 2008 life span being approximately 79 and 86, in men and women respectively. The aging rate will continue to rise in the future, yet fewer babies 
are born each year. Accordingly, Japan is inexorably aging. Our population has already peaked just short of 130 million, and we will face a population decline on a scale unprecedented in the developed world during this century. Although we have obtained this astonishing longevity, relatively inexpensively and within a short period of time, compared with other countries, we are facing a lot of problems associated with aging of our society, such as shortage of health-care professionals. Another problem is the increase of people with cognitive decline or dementia. The number of such people is estimated to be approximately 2 million and will definitely increase in the future (Ikejima et al., 2009; Meguro et al., 2007). Therefore, the support for dementia patients and their family becomes more and more important.

Our economic growth rate and technological achievements held the world in awe after World War II. However, in the future, Asian, as well as Western countries should watch Japan for another reason. The choices we make can affect the way in which the rest of the aging world tackles the same problem in years to come. Therefore, in this editorial I will describe what we have done for our society and what we should do as geriatricians and as members of the Japan Geriatrics Society, to meet the health-care needs of our aging population.

\section{Establishment of long-term care insurance (LTCI)}

One of the problems tackled was to develop a social insurance system for elderly people, especially for frail elderly, mainly for the purpose of community-based caregiving. Japan moved decisively toward "socialization of care" for the frail elderly by initiating public, mandatory long-term care insurance (LTCI) on April 1, 2000 (Arai, 
2001). Those aged 65 and over who need nursing care in their daily lives and those who require long-term care due to illnesses between the ages of 40 and 64 (specified illnesses) are eligible to receive the care services of LTCI. Consumers can choose the services and providers that they want. However, the increase in the number of elderly people requiring $\mathrm{LTCl}$, and the associated costs of these services, are imposing a burden on our society. The Ministry of Health, Labor and Welfare estimated that the number of elderly people requiring LTCI will increase from 1.5 million in 2000 to 5.2 million by 2025 . This increase in LTCl demand due to an increase in the elderly population will jeopardize our society, as well as the LTCI service itself. It has been reported that most institutions and businesses related to LTCI face difficulties in their operation. Most such care facilities employ care workers bettering their running. As care workers in the LTCI service receive insufficient rewards for their efforts, there is a high turnover rate, with many such workers leaving their jobs. Although the relationships between the economy and labor situation, and increases in LTCI demand are not clear, stable management of $\mathrm{LTCl}$, including the efficient running of related facilities, and high job satisfaction among care workers, is required for the sustainability of the LTCI system. Since 2006, LTCI regional comprehensive support centers have been introduced to deal with counseling related to elderly care and care management. Nurses, care workers, and physical and occupational therapists are running these centers. In spite of tough economic situations, I hope the Japanese government will decide to put more money into this system, although we should maintain our efforts to improve the cost-effectiveness of health care for the elderly, and decrease the number of frail elderly by preventing cardiovascular disease, 
osteoporosis, and geriatric syndrome. Many studies have been done by doctors, nurses, physical or occupational therapists, care workers, and the government to assess and improve the LTCI system (Kikuchi et al., 2006; Ozawa and Nakayama, 2005; Ikegami et al., 2003). We should try our best to improve this system in our country by supporting caregivers with professional training in improvement of long-term care for elderly patients, evaluation of long-term care services, and further assistance for care workers.

\section{The health insurance system for elderly 75 and over and comprehensive geriatric assessment}

The second problem tackled was the health insurance system specifically for elderly people aged 75 and over, which began on April 1, 2008. This has been unpopular due to several problems in the insurance system. However, the notion that people aged 75 and over should have their own primary-care physicians is useful for the transition to the home medical care. Some people are concerned about this system, because the "free-access" maintained in the Japanese medical system is no longer guaranteed for the very elderly. In spite of this concern, the idea should be generally implemented to avoid adverse drug effects related to polypharmacy, because elderly patients tend to see many doctors. This is also a good chance for our society to appreciate the role of geriatricians. Along with the enforcement of this insurance system, the Japan Geriatrics Society started a new education program for geriatricians and general practitioners to teach care of elderly patients. In the program, the Japan Geriatrics Society is trying to educate in the practical aspects of geriatric medicine 
required for the care of elderly patients and how to deal with clinical problems, especially geriatric syndrome. In this program the role of comprehensive geriatric assessment (CGA) has been stressed to maintain activities of daily living and quality of life of elderly patients. CGA is an integral part of geriatric care throughout the world, where the assessment of physiological, psychosocial, and cognitive aspects in elderly is essential (Rubenstein and Wieland, 1989). The frail elderly often have multiple chronic illnesses, functional disabilities, and psychosocial problems. Therefore, their needs obviously extend far beyond the treatment of any single medical condition. CGA also requires a multidisciplinary team approach and the use of guidelines and procedures to identify and address potentially reversible problems. The ultimate goal is to systematically restore and maintain the functions essential to preserving quality of life. Assessing how we offer medical examinations, treatment plans, rehabilitation, and the care services on the basis of a result of CGA is important. Among Japanese geriatricians, CGA is becoming more and more popular and many physicians are becomming ware of the importance of CGA. The applicability and effect of CGA on in-patient care, as well as community health care, have been reported (lizaka et al., 2008; Onishi et al., 2004). Thus, the medical care system for the very elderly is a touchstone of our society.

\section{Role of geriatricians in the aged society}

To ensure that every older person receives high-quality, patient-centered health care, the role of geriatricians and the Japan Geriatrics Society is enormous. The first department of geriatric medicine in Japan was founded in the University of Tokyo in 
1962. Our department of geriatric medicine at the Kyoto University Graduate School of Medicine is the second oldest and was established in 1967. Since then, many medical schools have established departments of geriatric medicine. However, at the moment less than $30 \%$ of Japan's 79 medical schools have departments of geriatric medicine. Therefore, not all the medical students receive the education in geriatric medicine and many graduate without even learning what the geriatric medicine is. Another sad fact is that some departments of geriatric medicine are managed without full professors. Generally speaking, undergraduate education in geriatrics in Japan emphasizes the theoretical aspects of the aging process and the features of disease in the elderly, but tends to omit attention to the practical aspects of care. In contrast, education in the United Kingdom and other countries places emphasis on practical aspects of elderly care. Thus, the education of geriatric medicine in our country is still remarkably poor in spite of the demand from society. I personally think that training in geriatric medicine should be required in all medical schools, and be taken into the medical-training system of young residents. Therefore, to expand the geriatrics knowledge base, increase the number of health-care professionals who employ the principles of geriatric medicine in caring for older persons, and recruit physicians and other health-care professionals into careers in geriatric medicine, the Japan Geriatrics Society is a key leader of change to achieve the goals of geriatric medicine and optimize the health of our aging population. At the moment the Japan Geriatrics Society has 6,134 members, and has approved 1,487 specialists of geriatrics. I hope that more and more young physicians are interested in geriatric medicine and are involved in the care of elderly people along with other health-care professionals. I do 
hope that our efforts will bring a brighter future for the Asian countries that follow Japan in terms of an aging society.

\section{Conclusions}

We have made significant progress in geriatrics and gerontology in the last two decades in Japan, as well as establishing our own health-care systems. Because Japan is the most aged country in the world - the second and third also being Asian countries - collaboration among Asian geriatric societies is important for the improvement of elderly health care in Asia.

Conflict of interest statement: None.

\section{References}

Arai, Y., 2001. Japan's new long-term care insurance. Lancet 26, 357, 1713.

lizaka, S., Tadaka, E., Sanada, H., 2008. Comprehensive assessment of nutritional status and associated factors in the healthy, community-dwelling elderly. Geriatr. Gerontol. Int. 8, 24-31.

Ikegami, N., Yamauchi, K., Yamada, Y., 2003. The long term care insurance law in Japan: impact on institutional care facilities. Int. J. Geriatr. Psychiatry. 18, 217-221.

Ikejima, C., Yasuno, F., Mizukami, K., Sasaki, M., Tanimukai, S., Asada, T., 2009. Prevalence and causes of early-onset dementia in Japan: a population-based study. Stroke 40, 2709-2714. 
Imuta, H., Yasumura, S., Abe, H., Fukao, A., 2001. The prevalence and psychosocial characteristics of the frail elderly in Japan: a community-based study. Aging (Milano) 13, 443-453.

Khaw, K.T., 1999. How many, how old, how soon? Br. Med. J. 20, 319, 1350-1352.

Kikuchi, K., Takahashi, R., Sugihara, Y., Inagi, Y., 2006. Five-year experience with the long-term care insurance system in Japan. J. Am. Geriatr. Soc. 54, 1014-1015.

Meguro, K., Ishii, H., Kasuya, M., Akanuma, K., Meguro, M., Kasai, M., Lee, E., Hashimoto, R., Yamaguchi, S., Asada, T., 2007. Incidence of dementia and associated risk factors in Japan: The Osaki-Tajiri Project. J. Neurol. Sci. 15, 260, 175-182.

Onishi, J., Umegaki, H., Suzuki, Y., Uemura, K., Kuzuya, M., Iguchi, A., 2004. The relationship between functional disability and depressive mood in Japanese older adult inpatients. J. Geriatr. Psychiatry. Neurol. 17, 93-98.

Ozawa, M.N. and Nakayama, S., 2005. Long-term care insurance in Japan. J. Aging Soc. Policy. 17, 61-84.

Rubenstein, L.Z., Wieland, D., 1989. Comprehensive geriatric assessment. Annu. Rev. Gerontol. Geriatr. 9, 145-192. 